\title{
Downregulated vimentin and upregulated E-cadherin in T1 stage non-small-cell lung cancer: does it suggest a mesenchymal-epithelial transition?
}

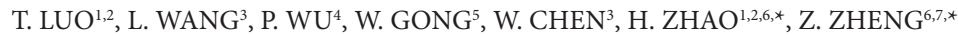

${ }^{1}$ Department of thoracic surgery, Zhejiang Cancer Hospital, Hangzhou 310022, People's Republic of China; ${ }^{2}$ Wenzhou Medical College, Wenzhou, 325035, People's Republic of China; ${ }^{3}$ Department of Biochemistry, Institute of Basic Medical Science, Hangzhou Medical College, Hangzhou, 310053, People's Republic of China; ${ }^{4}$ Department of pathology, Zhejiang Cancer Hospital, Hangzhou 310022, People's Republic of China; ${ }^{5}$ Biological samples library, Zhejiang Cancer Hospital, Hangzhou 310022, People's Republic of China; ${ }^{6}$ Zhejiang Key Laboratory of Diagnosis and Treatment Technology on Thoracic Oncology (Lung and Esophagus), Zhejiang Cancer Hospital, Hangzhou 310022, People's Republic of China; 'Zhejiang Research Institute of cancer, Zhejiang Cancer Hospital, Hangzhou 310022, People's Republic of China

*Correspondence: zhengzg@zjcc.org.cn,zhao_hg75@hotmail.com

\section{Received November 26, 2016/ Accepted February 8, 2017}

\begin{abstract}
Lung cancer has been a major threat to human health worldwide. Vimentin (VIM) and E-cadherin (E-cad) are molecular markers that play important roles in epithelial-mesenchymal transition (EMT), which has been shown to be correlated with tumor progression. Herein, we investigated the associations between clinicopathological parameters and VIM/E-cad expression in primary T1 stage non-small cell lung cancer (NSCLC). Real-time PCR was performed on RNA extracted from tumor tissue isolated from 54 patients with T1 stage NSCLC. Immunohistochemistry was used to measure the protein levels of VIM and E-cad. The paired-samples t-test, independent-samples t- test, Kappa test, and nonparametric test were used to perform statistical analyses. The expression of VIM were lower $(\mathrm{P}<0.001)$ and that of E-cad was higher $(\mathrm{P}<0.001)$ in tumor tissue when compared with the normal tissue at the transcriptional level. The RNA of VIM in adenocarcinomas was significantly higher than that found in squamous cell carcinomas $(\mathrm{P}<0.01)$. Moreover, the level of metastasis observed in the lymph node was significantly higher than that observed in metastasis outside of the lymph node $(\mathrm{P}<0.05)$. Vimentin protein had a lower profile in the tumor tissue, and the protein level of E-cad was higher in the tumor tissue. The IHC score of VIM in tumor tissue was found associated with both the pathological type and smoke index, and the score of E-cad was found to be related to visceral pleura involvement. In conclusions, VIM is downregulated and E-cad is upregulated in T1 stage NSCLC. Our study results suggest that a mesenchymal-epithelial transition may take place in the early-stage of tumor development, and that EMT occurs when the tumor develops into a certain stage.
\end{abstract}

Key words: non-small-cell lung cancer, vimentin, E-Cadherin, mesenchymal-epithelial transition, epithelial-mesenchymal transition

Lung cancer is one of the most commonly diagnosed malignancies in the world. In 2012, there were 1.8 million people diagnosed with lung cancer, and 1.59 million patients died worldwide [1]. In addition, lung cancer ranks higher than other cancers in Chinese males, and is the third most common cancer in Chinese females [1]. For many years, lung cancer has been a major threat to global public health. To date, it is acknowledged that susceptibility genes combined with environmental factors are of importance in the development of lung cancer and that this combination contributes to lung cancer risk [2]. However, the exact mechanism of lung cancer has not yet been completely discovered. Lung cancer is divided into small cell lung cancer and non-small cell lung cancer (NSCLC) according to its pathological type. T1 stage NSCLC is considered as early lesions, and its prognosis is relatively good. Nevertheless, T1 stage NSCLC upholds the risk of metastasis, and its prognosis differs between patients. Therefore, elucidating the precise trait of T1 stage NSCLC is pivotal to improve clinical outcomes and warrants further investigation.

Intermediate filaments (IFs) are one of the three major fibrous polymers of the cell, and play a role as cytoskeletal scaffolds in the nucleus and cytoplasm [3]. These filaments are dynamically regulated, fully integrated within the cellular framework and interact with a range of cellular proteins 
[4]. Furthermore, IFs have important functions in cellular migration [5], and are determining parameters in the cell invasiveness capacities, as their expression and composition could be used to evaluate the progression of cancers $[6,7]$. Vimentin (VIM) is a type III of IF, and is a mesenchymal marker of epithelial-mesenchymal transition (EMT), which is related with the acquisition of invasive properties [8]. The expression of VIM correlates with the invasive ability of epithelial cancers [9]. It is found abnormally expressed in breast cancer [10], hepatocellular carcinoma [11], renal cell carcinoma [12], cervical cancer [13], gastric carcinoma [14], colorectal carcinoma [15], esophageal cancer [16], thyroid cancer [17], ovarian cancer [18] and prostate cancer [19]. However, the relationship of VIM to NSCLC, especially T1 stage NSCLC, remains unclear.

E-cadherin (E-cad) is a molecule that has been employed as a biological marker of EMT [20], in addition to VIM. However, as an epithelial marker, E-cad plays a different role in the EMT process. The functions of E-cad include maintaining intact cell-cell interactions and inhibiting cell mobility, invasion and metastasis in human cancer [21]. Downregulation of E-cad expression is regarded as an endpoint of EMT-inducing signaling pathways [22]. Although many studies have demonstrated its biological functions, the role of E-cad in early stage tumor is worth exploring.

Thus, we examined the expression and levels of E-cad in the tumor tissue and normal tissue of T1 stage NSCLC patients, and then analyzed the association of clinicopathological data and VIM expression to reveal the role of VIM, E-cad and EMT in lung carcinogenesis.

\section{Methods and patients}

Patients. For this retrospective study, participant identification was initiated in February 2016. Medical records of patients with surgical treatment in the Zhejiang Cancer Hospital between August 2008 and October 2012 were collected. Cases for patients who were pathologically diagnosed as T1 stage NSCLC were selected, and those who met one of the following criterions were ruled out: multi-site tumor, had been pretreated with chemotherapy or radiotherapy, combined with other malignant diseases. Tumor grade and stage were defined according to the criteria of the World Health Organization (WHO) and the primary tumor, regional lymph nodes and distant metastasis (TNM) classification of the Union for International Cancer Control (UICC, eighth edition). This research was a retrospective study that used data solely from medical records and archived tissue samples, and was approved by the Medical Ethics Committee, Zhejiang Cancer Hospital (IRB-2015-176). Written informed consent was obtained from each patient before study enrollment.

Tissue specimens. Fifty-four T1 stage NSCLC patients were enrolled in the research. The specimens, including tumor and distal normal tissue, were collected under sterile conditions just after the lung tissues were removed, and were immediately snap frozen in liquid nitrogen. The specimens were stored at $-80^{\circ} \mathrm{C}$ for RNA extraction.

RNA extraction and cDNA synthesis. Total RNA was extracted from frozen sections of tumor and distal normal samples with a NucleoSpin ${ }^{\odot}$ TriPrep kit (MACHEREYNAGEL, Düren, Germany), according to the protocol provided by the manufacturer. RNA purity and concentration were detected by NanoDrop 1000 (Thermo Fisher Scientific, Waltham, MA, USA). Total RNA $(1 \mu \mathrm{g})$ was used for cDNA synthesis by PrimeScript ${ }^{\text {tix }}$ RT reagent Kit (TaKaRa, Dalian, Lianong, China), according to the instructions provided by the manufacturer.

Quantitative real-time PCR analysis. Amplification and melt curve analysis were performed using an ABI 7500 PCR system (Applied Biosystems). Reactions were carried out in a total volume of $20 \mu \mathrm{l}$, using a SYBR ${ }^{\oplus}$ Premix Ex Taq kit (TaKaRa). The primers for beta-actin (ACTB) were 5'-TGGCACCCAGCACAATGAA-3' (forward) and 5'CTAAGTCATAGTCCGCCTAGAAGCA-3' (reverse). The primers for VIM were 5'-CAATGAGTCCCTGGAACGCC-3' (forward) and 5'-TCCAGATTAGTTTCCCTCAGGTTC-3' (reverse).

The program setting for the PCR cycles were as follows: denaturation step at $95^{\circ} \mathrm{C}$ for $1 \mathrm{~min}$, the samples ran $40 \mathrm{ampli}$ fication cycles, each comprising denaturation $\left(95^{\circ} \mathrm{C}\right.$ for $\left.15 \mathrm{~s}\right)$, annealing and extension $\left(60^{\circ} \mathrm{C}\right.$ for $\left.1 \mathrm{~min}\right)$. All PCR reactions were run in triplicates and $\mathrm{ACTB}$ was used as a reference. Eight cases of cDNA were hybridized, packed and stored at $4^{\circ} \mathrm{C}$. Each PCR experiment used one pre-mixed template. For expression analysis, the experiment was designed to use the reference template as the control; thus, the relative quantification of gene expression in tested tissue was calculated using the equation: amount of target $=2^{-\Delta \Delta \mathrm{Ct}}, \Delta \Delta \mathrm{Ct}=\left(\mathrm{Ct}^{\mathrm{t}^{\text {ene }}}-\mathrm{Ct}_{\mathrm{ACTB}}\right)$ test- $\left(\mathrm{Ct}_{\text {gene }}-\mathrm{Ct}_{\mathrm{ACTB}}\right)$ reference. To confirm the specificity and accuracy of the PCR experiments, the PCR products were electrophoresed on a 2\% agarose gel and sequenced (Shanghai GeneCore BioTechnologies Company, Ltd., Shanghai, China).

Immunohistochemistry. Immunohistochemistry (IHC) staining was performed using standard IHC protocols. Tissue was cut to $5 \mu \mathrm{m}$ thickness, deparafnized in xylene, and rehydrated through graded alcohol. Next, $0.01 \mathrm{M}$ sodium citrate retrieval buffer $(\mathrm{pH} 6.0)$ at $125^{\circ} \mathrm{C}$ was used for antigen retrieval, and endogenous peroxidases were blocked using hydrogen peroxide. The sections were incubated with primary antibodies overnight at $4^{\circ} \mathrm{C}$ for VIM (rabbit monoclonal antibody, OriGene, Rockville, MD, USA) and E-cad (rabbit monoclonal antibody, Abcam, Cambridge, UK). Horseradish peroxidase detection was performed using SuperPicture ${ }^{\mathrm{TM}}$ detection system (OriGene), and PBS buffer solution was used to wash the sections. The sections were counterstained with hematoxylin, sealed with neutral gum, and analyzed by optical microscopy.

Immunohistochemistry was judged independently by two examiners. Distal normal tissue was used as a control. The immunoreactivity was assessed using the staining intensity score: 
0 for negative staining, 1 for weak intensity, 2 for moderate intensity, and 3 for strong intensity of staining.

Statistical analysis. Paired-samples Student's t-test was used to compare the RNA level of VIM and E-cad between normal and tumor tissue. Independent student's t-test was employed to analyze the association between clinicopathological parameters and both VIM and E-cad expression. Kappa's test was used to analyze the correlation between the IHC results of VIM and $\mathrm{E}$-cad. The criterion for statistical significance was set at $\mathrm{P}<0.05$ and all analysis were performed with SPSS 19.0 software.

\section{Results}

Patient characteristics were shown in Table 1. Patients with T1 stage NSCLC ( 40 males and 14 females) had a mean age of 61.2 years (range 38-79). Thirty-six of the patients were smokers, one-half of the subjects were classified as T1 a NSCLC (tumor larger than or equal to $1 \mathrm{~cm}$ and smaller than $2 \mathrm{~cm}$ ), and the remaining subjects were classified as T1b NSCLC. Twenty-four patients were diagnosed with adenocarcinoma and the remaining patients were diagnosed with squamous cell carcinomas. Lymph node metastasis was observed in 11 cases. The tumor cells in 20 patients were poorly differentiated
Table 1. Patient characteristics

\begin{tabular}{lc}
\hline Clinical and pathological parameters & Results \\
\hline Sample size & 54 \\
Gender (Male) & $74.1 \%$ \\
Age(year) & $61.20 \pm 8.98$ \\
Smoke index( $\geq 20$ pack-years) & $57.4 \%$ \\
Tumor diameter(cm) & $2.32 \pm 0.49$ \\
Pathological type (adenocarcinoma) & $44.4 \%$ \\
Tumor differentiation (poor) & $37.0 \%$ \\
Visceral pleura involvement & $14.8 \%$ \\
Venous invasion & $5.6 \%$ \\
Lymph node metastasis & $20.4 \%$ \\
\hline
\end{tabular}

Percentage was used for classified variables, and mean value \pm standard deviation was used for continuous variables.

compared to the remaining subjects, which had tumor cells that were moderately differentiated. In eight of the cases, there was evidence of visceral pleura involvement, while venous invasion was found in three cases.

Expression of VIM and E-cad. In the tumor tissue, the mRNA level of VIM were significantly lower (0.52 vs. 1.46 , 95\%CI: $-1.11 \sim-0.77, \mathrm{P}<0.001$ ) (Figure $1 \mathrm{~A}$ ), and the mRNA
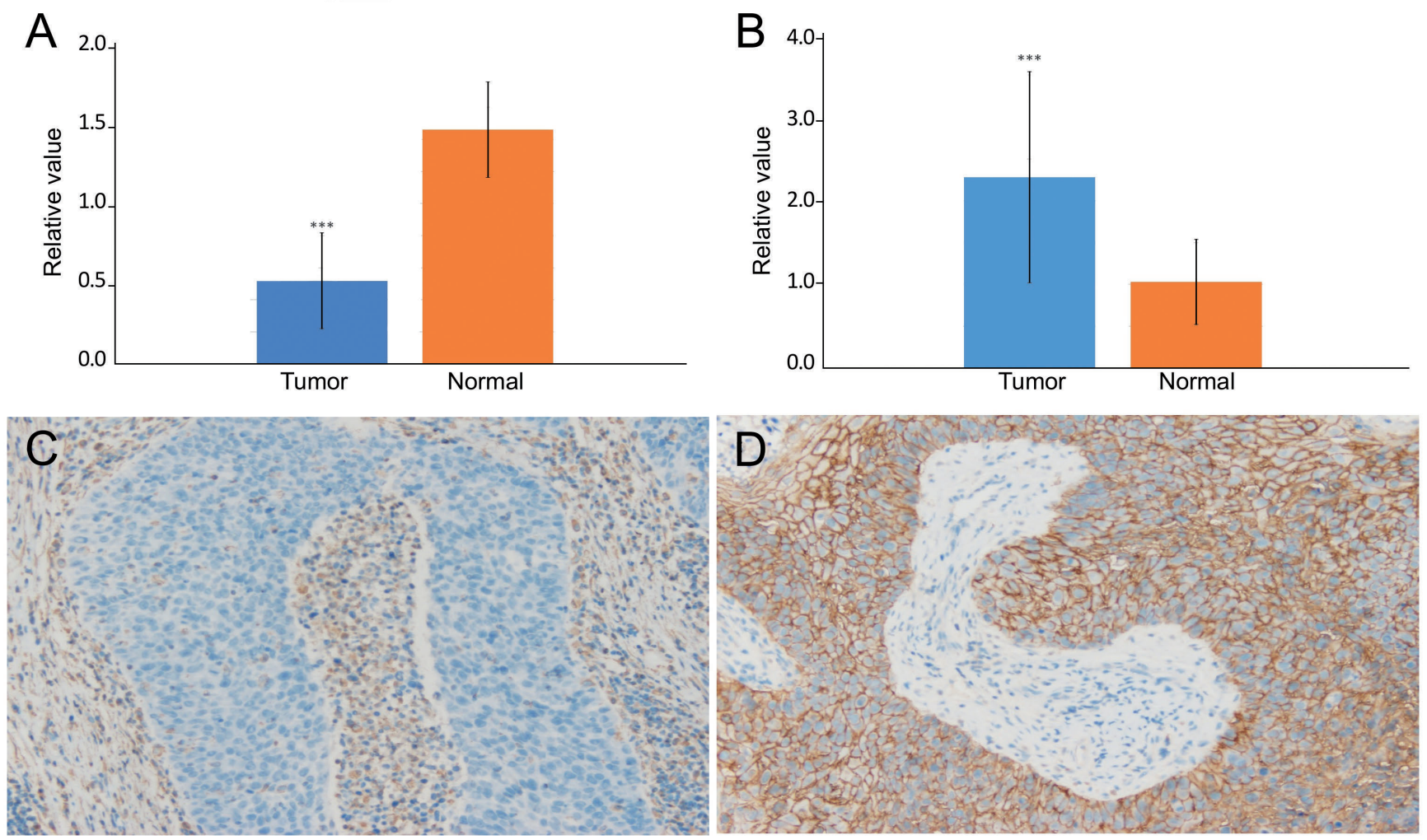

Figure 1. The expression of VIM and E-cad. (A) RT-PCR showed VIM was downregulated in tumor tissue (p<0.001). (B) RT-PCR showed E-cad was upregulated in tumor tissue $(p<0.001)$. (C) IHC showed a reduced expression of VIM was noted in the tumor tissue, and the expression was mainly detected in the cytoplasm. (D) IHC showed an increased expression of E-cad was noted in the tumor tissue, and the expression was mainly detected on the surface of cells. ${ }^{* * *}: \mathbf{p}<0.001$ 
level of E-cad was significantly higher when compared with the normal tissue (2.26 vs. $1.01,95 \% \mathrm{CI}$ : $0.72 \sim 1.79, \mathrm{P}<0.001$ ) (Figure 1B). To further examine the expression of VIM and E-cad, IHC was performed in 46 of all 54 cases, and VIM protein was found mainly in the cytoplasm of the cells. Compared with paired normal tissue, the protein of VIM showed a lower profile in the tumor tissue (Figure 1C). As expected, E-cad was found mainly on the surface of cells (Figure 1D). Compared with paired normal tissue, the expression of E-cad was increased in the tumor tissue. Furthermore, the results of the Kappa test revealed that the protein levels of VIM and Ecad were correlated in the same tumor tissue $(\mathrm{P}=0.001$, value of Kappa was 0.477).

RT-PCR and clinicopathological parameters. As shown in Figure 2A, VIM in adenocarcinomas was significantly higher than that in squamous cell carcinomas ( 0.64 vs. $0.42,95 \%$ CI: $0.06 \sim 0.36, \mathrm{P}=0.007)$. In addition, patients with lymph node metastasis had significantly higher VIM than patients without lymph node metastasis ( 0.69 vs. $0.48,95 \%$ CI: $0.02 \sim 0.41$, $\mathrm{P}=0.032$ ). Other clinicopathological parameters, including age, smoke index, tumor diameter, differentiation and venous invasion, had no evident effect on VIM expression. Moreover, the RT-PCR results for E-cad revealed no correlation with the clinicopathological parameters.

IHC scores and clinicopathological parameters. The IHC score of VIM in tumor tissue was found associated with both the pathological type and smoke index (Figure 2B). The score in adenocarcinomas was relatively higher than that in squamous cell carcinomas (1.64 vs. $1.00,95 \%$ CI: $0.05 \sim 1.23$, $\mathrm{P}=0.035$ ). In addition, patients with a smoke index of less than 20 pack-years had significantly higher IHC score of VIM than patients with a smoke index of greater than or equal to 20 pack-years (1.65 vs.1.04, 95\%CI: 0.02 1.21, $\mathrm{P}=0.045)$. Other clinicopathological parameters had no evident effect on the IHC score of VIM.

The IHC score of E-cad in tumor tissue was found to be associated with visceral pleura involvement (Figure 2C). The score in patients with visceral pleura involvement was relatively lower than that in patients without visceral pleura involvement ( 4.50 vs. $7.13,95 \% \mathrm{CI}$ : $0.36 \sim 4.90, \mathrm{P}=0.030$ ). Other clinicopathological parameters had no detectable effect on the IHC score of VIM.

\section{Discussion}

The EMT process has been a central issue in oncological studies. This process is described as a loss of epithelial marker proteins and their functions such as junction and apical-basal polarity, and the reorganization of their cytoskeleton $[23,24]$. Meanwhile, the upregulation of mesenchymal marker proteins enable the cells to gain the ability of migration and invasion during developmental morphogenesis [22, 23]. Recent studies have shown the EMT process results in endowing cancer cells with stem cell-like characteristics $[25,26]$, which enhances the ability of tumor cells to invade local tissues and resist immune-attacks [27]. Moreover, the EMT process is found to play an important role in tumor progression, including tumor dissemination, local invasion and metastasis [27-30].

The onset of EMT is associated with increased expression of VIM [31,32], and it has been shown that the downregulation of E-cad is an essential EMT step [33]. However, in our study, we discovered VIM was downregulated in T1 stage NSCLC, both at the transcriptional and translational level. Furthermore, our studies found that protein levels of E-cad were increased in $\mathrm{T} 1$
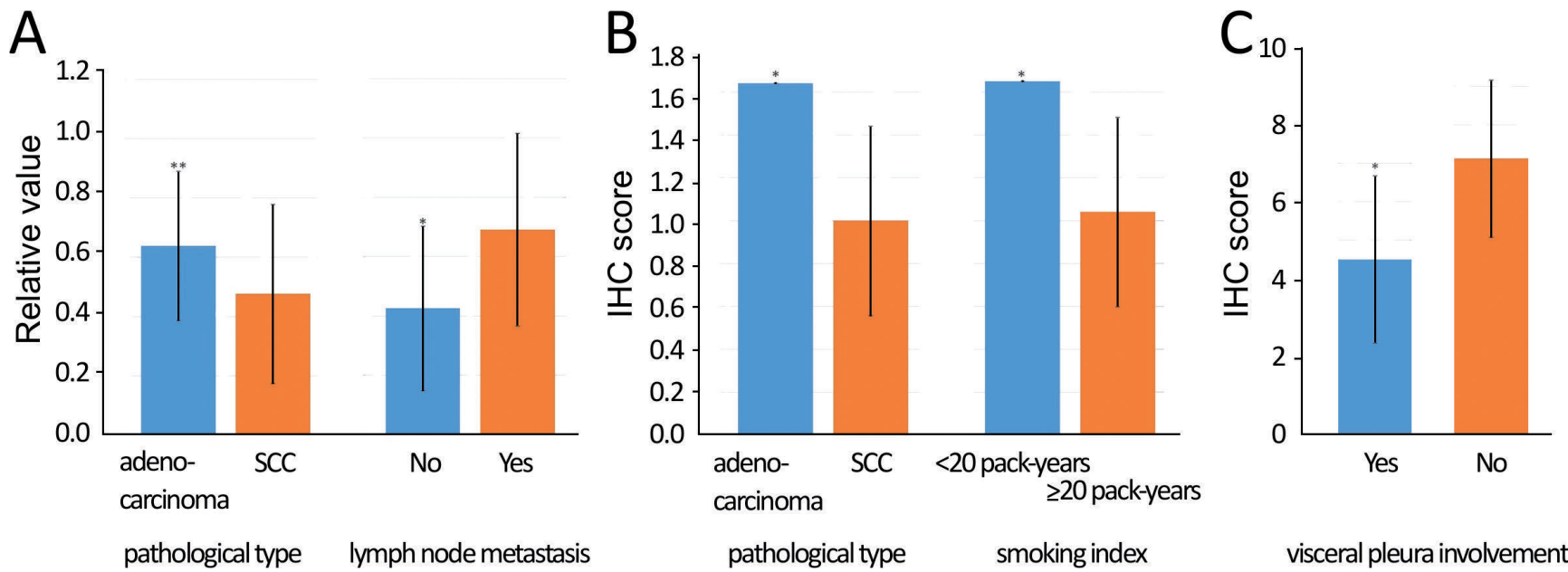

Figure 2. The correlation of clinicopathological parameters and the expression of VIM and E-cad. (A) VIM in adenocarcinomas was relatively higher than in squamous cell carcinomas ( $\mathbf{p}<0.01$ ), and in lymph node metastasis was relatively higher than in no lymph node metastasis ( $<<0.05)$. (B) The IHC score of VIM in adenocarcinomas was relatively higher than in squamous cell carcinomas $(\mathrm{p}<0.05)$, and in smoke index $<20$ pack-years was relatively higher than in smoke index $\geq 20$ pack-years $(\mathrm{p}<0.05)$. (C) The IHC score of E-cad in tumor with visceral pleura involved was relatively lower than in tumor without visceral pleura involved $(\mathrm{p}<0.01) .{ }^{*}: \mathrm{p}<0.05{ }^{* *}: \mathrm{p}<0.01$ 
stage NSCLC. These results were in contrast with the previously reported profile of EMT. It is possible that the results of our study provide evidence that the EMT process does not occur in T1 stage NSCLC. Previous reports have also shown that the EMT process is the final step of tumor de-differentiation [34], and primary tumor may be one of the bases of the EMT process, as the tumor microenvironment has a significant effect on the EMT process [35].

It is well established that VIM is a mesenchymal marker [8], and E-cad is an epithelial marker [21]. The overexpressed epithelial marker and downregulated mesenchymal marker in T1 stage NSCLC may suggest a process of mesenchymal-epithelial transition (MET) in the tumorigenesis, as upregulation of $\mathrm{E}$ cad is reported to be a mark for MET [36]. A previous study showed that the MET process is able to promote metastatic growth [37], and is essential for establishing macrometastases [38]. We infer that in the early stage or tumorigenesis of NSCLC, the MET process plays a major role. The downregulation of mesenchymal markers and upregulation of epithelial markers could promote the division of malignant cells and local invasion. Taken together, we believe that these regulatory products attribute to the vast number of patients diagnosed with early-stage NSCLC in the clinical setting.

To support our finding, we compared our results to other reports and showed that our inference is consistent with previous studies. Although Prudkin et al. [39] demonstrated both lung adenocarcinoma and squamous cell carcinoma had high levels of VIM expression, preneoplasia had significantly lower expression of VIM than normal tissue. An in vitro study revealed that mesenchymal markers were absent in precursor lesions, both hyperplastic and adenomatoid, and suggested that the EMT progress occurred at a later stage [40]. Liu et al. [41] reported VIM expression was found in later cancer stages as well.

The EMT process takes place only if the tumor has developed into a certain stage. Furthermore, the EMT process indicates reduced cell proliferation [37], and enhanced ability of tumor cells to metastasis [22]. The higher RNA level of VIM in tumors with lymph node metastasis in our study could be the symbol of EMT onset. We found that the RNA level of VIM in adenocarcinomas was relatively higher than that in squamous cell carcinomas, both at the transcriptional level and translational level, which may suggest that the EMT process is prone to occur in adenocarcinomas at an earlier stage than squamous cell carcinomas. In accordance with our clinical experience, the adenocarcinoma is more likely to have lymph node metastasis than squamous cell carcinoma during the early stage.

In addition, we found that the expression of E-cad was associated with visceral pleura involvement, as the level of E-cad in the tumor with visceral pleura involvement was relatively lower than in the tumor without visceral pleura involvement. It was reported that during lung carcinogenesis, the impaired expression of E-cad leads to strong invasive behavior [42]. Multiple studies suggested that in patients with NSCLC, reduced
E-cad expression was significantly correlated with increased local invasion [43-45]. The lower profile of E-cad in visceral pleura involved NSCLC may suggest that the EMT process occurred in tumors with stronger invasive ability.

Reports show that VIM is associated with tumor differentiation. In prostate cancer, VIM is detected mainly in poorly differentiated cancers and is associated with bone metastases $[27,46]$. Al-Saad et al. [47] revealed that the expression of VIM was significantly related with the tumor differentiation of NSCLC, and that high VIM levels were observed in $61 \%$ of poorly differentiated tumors, $39 \%$ of moderately differentiated tumors and no expression of VIM was observed in well-differentiated tumors. Similarly, we examined tumors at the early-stage as well as the late-stage. We found that VIM expression was not related to tumor differentiation in $\mathrm{T} 1$ NSCLC. This suggests that the differences of VIM in poorly, moderate and well-differentiated tumors may occur in a relatively late-stage. Furthermore, the role the EMT process plays in tumor differentiation is suggested as well, as VIM is a key marker of the EMT process.

VIM was reported as being overexpressed in various epithelial cancers [9], including NSCLC [27], and E-cad shows a low profile in most tumors, such as gastric cancer [48], breast cancer [49], and oral squamous cell carcinogenesis [50]. Thus, the object of these studies is not limited in cancer patients at the early-stage. As the EMT process takes place in tumor progression, the level of VIM in the tumor rises and the level of E-cad falls along with the tumor stage. Moreover, our findings are consistent with the results of previous reports.

In summary, this study found that in T1 stage NSCLC, VIM was downregulated and E-cad was upregulated. In addition, we found that the pathological type and lymph node metastasis were correlated with VIM at the transcriptional level, pathological type and smoke index were correlated with VIM at the translational level, and visceral pleura involvement was associated with E-cad at the translational level. Our results suggest that there may be a mesenchymal-epithelial transition that takes place in the early-stage of tumor development, and that EMT occurs when the tumor has developed into a certain stage. As the details surrounding the role of the MET process in tumorigenesis remain unclear, additional studies are warranted to elucidate the mechanism of action.

Acknowledgements: This work was supported by 1022 talents training program of Zhejiang cancer hospital, the third level in Zhejiang province "151 talents project", Natural Science Foundation of Zhejiang (LY14H160013), General Research Project of Zhejiang Medical College (2013XZB02) and grants from the second batch of Medicine Key Project of Zhejiang Province. All the authors declare no conflict of interest.

\section{References}

[1] FORMAN D, FERLAY J. The global and regional burden of cancer. p. 16-53. In: Stewart BW and Wild CP (Eds.). World 
Cancer Report 2014, 1st Edition, IARC, Lyon 2014, 630 pp. ISBN 978-92-832-0443-5.

[2] TOH CK, GAO F, LIM WT, LEONG SS, FONG KW et al. Never-smokers with lung cancer: epidemiologic evidence of a distinct disease entity. J Clin Oncol. 2006; 24: 2245-2251. https://doi.org/10.1200/JCO.2005.04.8033

[3] ALBERTS B, JOHNSON A, LEWIS J, RAFF M, ROBERTS K, WALTER P. (Eds.) Molecular Biology of the Cell, 4th Edition, Garland Science, New York 2002, 1463 pp. ISBN 9780815332183

[4] COULOMBE PA, WONG P. Cytoplasmic intermediate filaments revealed as dynamic and multipurpose scaffolds. Nat Cell Biol 2004; 6: 699-706. https://doi.org/10.1038/ncb0804-699

[5] LEDUC C, ETIENNE-MANNEVILLE S. Intermediate filaments in cell migration and invasion the unusual suspects. Curr Opin Cell Biol 2015; 32: 102-112. https://doi. org/10.1016/j.ceb.2015.01.005

[6] CHUNG BM, ROTTY JD, COULOMBE PA. Networking galore: intermediate filaments and cell migration. Curr Opin Cell Biol 2013; 25: 600-612. https://doi.org/10.1016/j. ceb.2013.06.008

[7] ERIKSSON JE, DECHAT T, GRIN B, HELFAND B, MENDEZ $\mathrm{M}$ et al. Introducing intermediate filaments: from discovery to disease. J Clin Invest 2009; 119: 1763-1771. https://doi. org/10.1172/JCI38339

[8] MENDEZ MG, KOJIMA S, GOLDMAN RD. Vimentin induces changes in cell shape, motility, and adhesion during the epithelial to mesenchymal transition. FASEB J 2010; 24: 1838-1851. https://doi.org/10.1096/fj.09-151639

[9] SATELLI A, LI S. Vimentin in cancer and its potential as a molecular target for cancer therapy. Cell Mol Life Sci 2011; 68: 3033-3046. https://doi.org/10.1007/s00018-011-0735-1

[10] VORA HH, PATEL NA, RAJVIK KN, MEHTA SV, BRAHMBHATT BV et al. Cytokeratin and vimentin expression in breast cancer. Int J Biol Markers 2009; 24: 38-46. https://doi. org/10.5301/JBM.2009.4965

[11] KIM KR, CHOI HN, LEE HJ, BAEK HA, PARK HS et al. A peroxisome proliferator-activated receptor gamma, antagonist induces VIM cleavage and inhibits invasion in high-grade hepatocellular carcinoma. Oncol Rep 2007; 18: 825-832.

[12] LEROY X, ZINI L, BUOB D, BALLEREAU C, VILLERS A et al. Renal cell carcinoma with rhabdoid features: an aggressive neoplasm with overexpression of p53. Arch Pathol Lab Med 2007; 131: 102-106.

[13] CORVER WE, TER HAAR NT, DREEF EJ, MIRANDA NF, PRINS FA et al. High-resolution multi-parameter DNA flow cytometry enables detection of tumour and stroreal cell subpopulations in paraffin-embedded tissues. J Pathol 2005; 206: 233-241. https://doi.org/10.1002/path.1765

[14] YAZIJI H, BATTIFORA H, BARRY TS, HWANG HC, BACCHI CE et al. Evaluation of 12 antibodies for distinguishing epithelioid mesothelioma from adenocarcinoma: identification of a three-antibody immunohistochemical panel with maximal sensitivity and specificity. Mod Pathol 2006; 19: 514-523. https://doi.org/10.1038/modpathol.3800534

[15] SHIRAHATA A, SAKATA M, SAKURABA K, GOTO T, MIZUKAMI $\mathrm{H}$ et al. Vimentin methylation as a marker for advanced colorectal carcinoma. Anticancer Res 2009; 29: 279-281.

[16] USAMI Y, SATAKE S, NAKAYAMA F, MATSUMOTO M, OHNUMA K et al. Snail-associated epithelial-mesenchymal transition promotes oesophageal squarnous cell carcinoma motility and progression. J Pathol 2008; 215: 330-339. https:// doi.org/10.1002/path.2365

[17] VASKO V, ESPINOSA AV, SCOUTEN W, HE H, AUER H et al. Gene expression and functional evidence of epithelialto-mesenchymal transition in papillary thyroid carcinoma invasion. Proc Natl Acad Sci U S A 2007; 104: 2803-2808. https://doi.org/10.1073/pnas.0610733104

[18] COLOMIERE M, FINDLAY J, ACKLAND L, AHMED N. Epidermal growth factor-induced ovarian carcinoma cell migration is associated with JAK2/ STAT3 signals and changes in the abundance and localization of alpha6betal integrin. Int J Biochem Cell Biol 2009; 41: 1034-1045. https://doi. org/10.1016/j.biocel.2008.09.018

[19] WEI J, XU G, WU M, ZHANG Y, LI Q et al. Overexpression of vimentin contributes to prostate cancer invasion and metastasis via src regulation. Anticancer Res 2008; 28: 327-334.

[20] LEE GA, HWANG KA, CHOI KC. Roles of Dietary Phytoestrogens on the Regulation of Epithelial-Mesenchymal Transition in Diverse Cancer Metastasis. Toxins (Basel) 2016; 8: 6. https://doi.org/10.3390/toxins8060162

[21] PERL AK, WILGENBUS P, DAHL U, SEMB H, CHRISTOFORI G. A causal role for E-cadherin in the transition from adenoma to carcinoma. Nature 1998; 392: 190-193. https:// doi.org/10.1038/32433

[22] THIERY JP, SLEEMAN JP. Complex networks orchestrate epithelial-mesenchymal transitions. Nat Rev Mol Cell Biol 2006; 7: 131-142. https://doi.org/10.1038/nrm1835

[23] THIERY JP, ACLOQUE H, HUANG RY, NIETO MA. Epithelial-mesenchymal transitions in development and disease. Cell 2009; 139: 871-890. https://doi.org/10.1016/j. cell.2009.11.007

[24] TSAI JH, YANG J. Epithelial-mesenchymal plasticity in carcinoma metastasis. Genes Dev 2013; 27: 2192-2206. https:// doi.org/10.1101/gad.225334.113

[25] NAHAS GR, PATEL SA, BLISS SA, RAMESHWAR P. Can breast cancer stem cells evade the immune system? Curr Med Chem 2012; 19: 6036-6049. https://doi. org/10.2174/0929867311209066036

[26] ESTEBAN MA, BAO X, ZHUANG Q, ZHOU T, QIN B et al. The mesenchymal-to-epithelial transition in somatic cell reprogramming. Curr Opin Genet Dev 2012; 22: 423-428. https://doi.org/10.1016/j.gde.2012.09.004

[27] ZHOU L, YU L, WU S, FENG Z, SONG W et al. Clinicopathological significance of KAI1 expression and epithelial-mesenchymal transition in non-small cell lung cancer. World J Surg Oncol 2015; 13: 234. https://doi.org/10.1186/ $\underline{\text { s12957-015-0657-8 }}$

[28] FUYUHIRO Y, YASHIRO M, NODA S, KASHIWAGI S, MATSUOKA J et al. Clinical significance of vimentin-positive gastric cancer cells. Anticancer Res 2010; 30: 5239-5243.

[29] TAKEMURA K, HIRAYAMA R, HIROKAWA K, INAGAKI $\mathrm{M}$, TSUJIMURA $\mathrm{K}$ et al. Expression of vimentin in gastric 
cancer: a possible indicator for prognosis. Pathobiology 1994; 62: 149-154. https://doi.org/10.1159/000163895

[30] LANG SH, HYDE C, REID IN, HITCHCOCK IS, HART CA et al. Enhanced expression of vimentin in motile prostate cell lines and in poorly differentiated and metastatic prostate carcinoma. Prostate 2002; 52: 253-263. https://doi.org/10.1002/ pros. 10088

[31] WANG N, STAMENOVIC D. Mechanics of vimentin intermediate filaments. J Muscle Res Cell Motil 2002; 23: 535-540. https://doi.org/10.1023/A:1023470709071

[32] CHU S, XU H, FERRO TJ, RIVERA PX. Poly (ADP-ribose) polymerase-1 regulates vimentin expression in lung cancer cells. Am J Physiol Lung Cell Mol Physiol 2007; 293: 11271134. https://doi.org/10.1152/ajplung.00197.2007

[33] HARRIS TJ, TEPASS U. Adherens junctions: from molecules to morphogenesis. Nat Rev Mol Cell Biol 2010; 11: 502-514. https://doi.org/10.1038/nrm2927

[34] THIERY JP. Epithelial-mesenchymal transitions in tumour progression. Nat Rev Cancer 2002; 2: 442-454. https://doi. org/10.1038/nrc822

[35] LI H, XU F, LI S, ZHONG A, MENG X et al. The Tumor Microenvironment: an Irreplaceable Element of Tumor Budding and Epithelial-mesenchymal Transition-mediated Cancer Metastasis. Cell Adh Migr 2016; 10: 434-446. https:// doi.org/10.1080/19336918.2015.1129481

[36] CERVANTES-ARIAS A, PANG LY, ARGYLE DJ. Epithelial-mesenchymal transition as a fundamental mechanism underlying the cancer phenotype. Vet Comp Oncol 2013; 11: 169-184. https://doi.org/10.1111/j.1476-5829.2011.00313.x

[37] UMBREIT C, ERBEN P, FABER A, HOFHEINZ RD, SCHULTZ JD et al. Lapatinib-induced mesenchymal-epithelial transition in squamous cell carcinoma cells correlates with unexpected alteration of $\beta$-catenin expression. Oncol Lett 2016; 11: 2715-2724. https://doi.org/10.3892/ol.2016.4293

[38] GUO F, PARKER KERRIGAN BC, YANG D, HU L, SHMULEVICH I et al. Post-transcriptional regulatory network of epithelial-to-mesenchymal and mesenchymal-toepithelial transitions. J Hematol Oncol 2014; 7: 19. https://doi. org/10.1186/1756-8722-7-19

[39] PRUDKIN L, LIU DD, OZBURN NC, SUN M, BEHRENS C et al. Epithelial-to-mesenchymal transition in the development and progression of adenocarcinoma and squamous cell carcinoma of the lung. Mod Pathol 2009; 22: 668-678. https:// doi.org/10.1038/modpathol.2009.19

[40] BLANCO D, VICENT S, ELIZEGI E, PINO I, FRAGA MF et al. Altered expression of adhesion molecules and epithelial-mesenchymal transition in silica-induced rat lung carcinogenesis. Lab Invest 2004; 84: 999-1012. https://doi. org/10.1038/labinvest.3700129
[41] LIU CY, LIN HH, TANG MJ, WANG YK. Vimentin contributes to epithelial-mesenchymal transition cancer cell mechanics by mediating cytoskeletal organization and focal adhesion maturation. Oncotarget 2015; 6: 15966-15983. https://doi.org/10.18632/oncotarget.3862

[42] SALON C, LANTUEJOUL S, EYMIN B, GAZZERI S, BRAMBILLA $C$ et al. The E-cadherin- $\beta$-catenin complex and its implication in lung cancer progression and prognosis. Future Oncol 2005; 1: 649-660. https://doi. org/10.2217/14796694.1.5.649

[43] KASE S, SUGIO K, YAMAZAKI K, OKAMOTO T, YANO $\mathrm{T}$ et al. Expression of E-cadherin and beta-catenin in human non-small cell lung cancer and the clinical significance. Clin Cancer Res 2000; 6: 4789-4796. https://doi.org/10.1016/ s0169-5002(00)80667-4

[44] SHIBANUMA H, HIRANO T, TSUJI K, WU Q, SHRESTHA $\mathrm{B}$ et al. Influence of E-cadherin dysfunction upon local invasion and metastasis in non-small cell lung cancer. Lung Cancer 1998; 22: 85-95. https://doi.org/10.1016/S01695002(98)00053-1

[45] BREMNES RM, VEVE R, GABRIELSON E, HIRSCH FR, BARON A ET AL. HIGH THROUGHPUT TISSUE MICROARRAY analysis used to evaluate biology and prognostic significance of the E-cadherin pathway in non-small cell lung cancer. J Clin Oncol 2002; 20: 2417-2428. https://doi. org/10.1200/JCO.2002.08.159

[46] ZHAO Y, YAN Q, LONG X, CHEN X, WANG Y. Vimentin affects the mobility and invasiveness of prostate cancer cells. Cell Biochem Funct 2008; 26: 571-577. https://doi.org/10.1002/ $\underline{\text { cbf. } 1478}$

[47] AL-SAAD S, AL-SHIBLI K, DONNEM T, PERSSON M, BREMNES RM et al. The prognostic impact of NF-kB p105, vimentin, E-cadherin and Par6 expression in epithelial and stromal compartment in non-small-cell lung cancer. Br J Cancer 2008; 99: 1476-1483. https://doi.org/10.1038/ sj.bjc. 6604713

[48] LIU AN, ZHU ZH, CHANG SJ, HANG XS. Twist expression associated with the epithelial-mesenchymal transition in gastric cancer. Mol Cell Biochem 2012; 367: 195-203. https:// doi.org/10.1007/s11010-012-1333-8

[49] OKA H, SHIOZAKI H, KOBAYASHI K, INOUE M, TAHARA $\mathrm{H}$ et al. Expression of E-cadherin cell adhesion molecules in human breast cancer tissues and its relationship to metastasis. Cancer Res 1993; 53: 1696-1701.

[50] CHAW SY, MAJEED AA, DALLEY AJ, CHAN A, STEIN S et al. Epithelial to mesenchymal transition (EMT) biomarkers-E-cadherin, beta-catenin, APC and Vimentin. Oral Oncol 2012; 48: 997-1006. https://doi.org/10.1016/j.oraloncology.2012.05.011 